\title{
An Empirical Investigation Into The Administrative Procedures Taken In Response To The Detection Of Medical Errors Within Acute Care Hospitals In Pennsylvania \\ Monica L. Law, Bloomsburg University, USA
}

\begin{abstract}
This researcher investigates the procedures taken by healthcare administrators within Pennsylvania acute care hospitals with respect to the detection of medical errors in order to provide corrective measures. In response to structured interview questions, the overwhelming majority of research participants stated that the procedures for corrective actions focused upon various training interventions as deemed appropriate by management. However, scholarly literature states that the majority of medical errors do not occur due to the lack of competence, skills, or knowledge of healthcare professionals. Thus, using training interventions to solve nontraining problems may not prove effective. The outcome of the study has lead to several important implications for the healthcare industry. Lastly, further research was suggested as it relates to patient safety and the reduction of medical errors.
\end{abstract}

Keywords: medical errors; corrective action; training; needs assessment; healthcare management; error reporting systems; system failures

\section{INTRODUCTION}

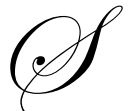

tudies dated back to the 1960s have shown that the occurrence of medical errors has been a relevant problem in the United States. More recently, To Err is Human: Building a Safer Health System, a report distributed by the Institute of Medicine, has heightened awareness to the number of medical error occurrences in the United States (Corrigan, Donaldson, \& Kohn, 2000). In addition, popular media have joined in the effort to make the American public aware of the danger that may be encountered in healthcare facilities across the country.

It has been stated that healthcare professionals are among the most educated and dedicated workforce in any industry, so why do so many medical errors exist in our healthcare facilities today? Studies suggest that the problem does not lie with healthcare workers, but with the systems in which these people work. Systems need to be made safer in order to reduce the occurrence of medical errors (Corrigan, Donaldson, \& Kohn, 2000).

Keepnews (2000) stated that "in order to properly address errors, systems must be identified and corrected before reductions in error rates can occur" (p. 77). Researchers had begun to identify medical errors as a widespread systems problem many years ago (Leape, 1994). However, it has been the Institute of Medicine's (2000) recently published report To Err is Human: Building a Safer Health System that has the country searching for system approaches that can be implemented and consequently help reduce the number of medical errors that occur in the United States each year. 


\section{LITERATURE REVIEW}

The occurrence of medical errors have been receiving substantial attention and the medical community, government, and healthcare agencies are all working together in an attempt to find solutions that will aid in the reduction of preventable medical errors that occur each year within healthcare facilities. It is relevant to have an understanding of how the medical community defines an error. The Institute of Medicine has defined an error as "the failure of a planned action to be completed as intended or the use of wrong plan to achieve an aim" (Corrigan, Donaldson, \& Kohn, 2000, p. 28). More specifically, an error can be construed as a misdiagnosis, a wrong procedure performed, a medication dosing mistake, faulty equipment, and a host of other unintended acts that result in failure.

System failures have been identified as a major contributor to the occurrence of medical errors. Subsequently, research has changed its focus from individuals to systems, specifically, improving the systems to reduce errors (Adams, Jaffe, \& Rosenbloom, 2001). In addition, Cooper (2001) states "even though effective remedies do exist, much research is needed in the area of medical errors in order to learn about the underlying causes of the errors and system failures" (p. 4).

O'Leary (2000) explains that in order to increase knowledge about why errors occur in healthcare and apply that information in a manner that will enhance patient safety, a cultural shift will be necessary in regard to how society views and treats medical errors. A blame-free, protected environment must be established in order to encourage the systematic surfacing and reporting of adverse events. In conclusion, Pate \& Stajer (2000) state:

In order to avoid blame and its consequences, hospital administration must concentrate on questions about the system, not about specific individuals or departments. The underlying systems flaws that have occurred should be the focus, not what specific individual, or department, made the error. (p. 8)

\section{PURPOSE}

The ultimate goal of this study was to help providers of healthcare within Pennsylvania acute care hospitals find solutions to the ever-present problem of the occurrence of medical errors. Scholarly literature states that the majority of medical errors occur due to systems that breakdown and fail healthcare workers. This study sought to provide new knowledge in regard to where one particular system may be breaking down, specifically the error reporting system. The purpose of this study was twofold; 1) to develop two structured interview questionnaires, and 2) to conduct structured interviews as a means to collect data that focused on the occurrence of medical errors; specifically through assessing the error reporting systems within a sample of Pennsylvania acute care hospitals.

\section{RESEARCH QUESTION}

Research Question: Within the sampled Pennsylvania acute care hospital error reporting systems; are procedures in place, once a medical error has been detected, in order to correct the error?

Using a qualitative methodology, perceptions of twenty-two healthcare professionals and fifteen patients were collected through structured interviews. More specifically, twelve patient safety officers, ten nurses, and fifteen patients were interviewed. Interviews averaged forty-three minutes in length. The research question provided the framework for data organization and for interpreting the perceptions of the research participants. This paper focuses on the Research Question which states: "Within the sampled Pennsylvania acute care hospital error reporting systems; are procedures in place, once a medical error has been detected, in order to correct the error?

This research question was aimed at obtaining information about the procedures used within the sampled Pennsylvania acute care hospitals' error reporting systems, procedures specific to corrective actions. Information for this question was obtained during interviews with patient safety officers and the nurses. 


\section{FINDINGS}

In analyzing responses from this research question, it was found that, yes, procedures are in place once a medical error has been detected in order to correct the error. However, most noteworthy, in regard to the responses involve the type of corrective action that takes place. The overwhelming majority of both patient safety officers and nurses stated that the corrective actions that take place involve training or re-education. It may be that errors are reoccurring due to the types of corrective actions taken. More specifically, training and education may not solve a system problem that needs management's attention in order to rectify.

Certainly new technologies, tools, and other information make it both pertinent and relevant to continually train or educate hospital personnel. The medical field is not static, therefore staying current is very important. However, using this approach to reduce the number of errors that occur may not be effective. In the event that a corrective action was warranted, the majority of respondents stated that training or education were the main modes of action. The overwhelming majority of respondents said that the focus was on re-training, in-services, and education, such as re-reading policies.

\section{CONCLUSIONS}

The types of corrective actions taken may be a significant breakdown within the system, as literature suggests that a great number of errors do not occur due to the lack of training or competence of healthcare professionals (Corrigan, Donaldson, \& Kohn, 2000). A few respondents stated that other types of interventions were utilized as well, but the overwhelming majority chose training as the main method for aiding in the reduction of medical errors. Even though the training efforts, in the majority of hospitals, are conducted on-the job, which most likely yields a better investment as opposed to off-the-job efforts, there are still factors to consider. Rothwell (2002) states:

Although on-the-job training may be a better investment, (as opposed to off-the-job) since research shows that it is consistently more likely to be applied, the fact is that training alone is unlikely to produce on-the-job behavioral or performance change (p. 11).

In addition, even if a training intervention would be warranted, management must be aware of the transfer of training. Specifically, transfer of training ensures that the learning objectives and content of the training session are transferred to daily work activities (Noe, 2002). It is relevant to add that individuals typically forget about $80 \%$ of what they hear within forty-eight hours. "If they sit through a classroom training session-or even participate in online training-they forget about 80 percent two days later" (Rothwell, 2002, p. 11). Knowing this provides an added challenge to hospital administration. If in fact, they choose training interventions as the main means to address the occurrence of medical errors, they must somehow measure and evaluate the transfer of training.

It may be that the corrective actions taken do not promote learning; therefore a breakdown exists between the correction and the prevention stage. It may be very difficult to promote reoccurrence prevention if inappropriate corrective actions are taken. There are, of course, times when training and education will be appropriate. However, in a general sense, simply re-training or re-educating staff when an error occurs may not be an effective learning tool to promote reoccurrence.

\section{RECOMMENDATIONS}

Based upon the findings and conclusions the following suggestion is provided to healthcare management. First, it is suggested that administration conduct needs assessments within their organizations in order to address the concern of the occurrence of medical errors. Rothwell (2002) states that management action is necessary to solve problems created by the organization's work environment. Rothwell goes on to state that "No amount of training will solve a problem caused by lack of supervision, lack of organizational planning, ill-conceived reward systems that reinforce the wrong behaviors or results, or other such problems that stem from the work environment." (p. 7). 
In addition, the environment may need to be assessed. The organizational goals, the mission, the vision, philosophies, policies, procedures, leadership structure and style, and objectives may need to be assessed in order to verify that they are conducive to the needs that are present when developing a plan of action to reduce the occurrence of errors. Noe (2002) states that "training may not even be necessary and result waste of time and money. Employees may have the knowledge, skills, or behavior they need but simply not be motivated to use them" (p. 7).

The human factor approach may be used to understand where and why systems break down. In this approach, the process of the error is examined with focus on looking at the causes, circumstances, conditions, associated procedures, and other factors connected with the event. Much of the work in human factor research focuses on improving the human-systems interface by designing better systems and processes. This may include simplifying or standardizing procedures, or redesigning equipment to improve the human-machine interface (Corrigan, Donaldson, \& Kohn, 2000).

When addressing human performance, specifically assuming that human performance is the cause of many errors in healthcare, management should assess in order to find improvement opportunities and distinguish those that lend themselves to training solutions from those that do not. Training will only solve problems resulting from an individual's lack of knowledge, skill, or appropriate attitude. Training will not solve problems that stem from management practices such as the lack of adequate planning, lack of job performance standards or work expectations, lack of feedback, or lack of supervision (Rothwell, 1996). Rothwell (1996) also suggests that as little as $20 \%$ of all human performance problems are attributable to individual employees, as much as $80 \%$ of all such problems are attributable to the work environment or systems in which the employees must work.

Human factors specialists describe complex systems, such as healthcare organizations, as inverted pyramids. The broad blunt end on top consists of administrators, managers, and regulators; these are the people who set policies and enforce rules. Consequences of poor decisions made at this end of the pyramid can be viewed as latent failures as they can lie dormant for a long period of time before becoming visible. The sharp end of the pyramid consists of doctors and nurses; these are the people who interact directly with patients. Their mistakes are viewed as active failures, as they can be more obvious due to immediate, and often serious, consequences. Safety researchers have suggested that the behavior of those at the sharp end must be viewed in the context of the demands and constraints established by the people at the blunt end. In addition, accident investigators reveal consistently that the ability of people at the sharp end to prevent adverse incidents depends upon many factors determined at the blunt end, rather than isolated acts made by any one individual (MacReady, 2000).

\section{SUMMARY}

In summary, hospital management may want to analyze the error reporting systems employed within their organizations in order to find root causes of these perceived system failures. It is most likely easier to implement a training intervention when something goes wrong, but it appears that it is time to look beyond training and assess the fundamental issues within the systems of healthcare in order to combat the occurrence of medical errors.

\section{AUTHOR INFORMATION}

Dr. Monica Law received her Ph.D. from the Pennsylvania State University and is a licensed Radiologic Technologist. Her career began in an acute care hospital as a staff technologist. Then, she moved into a management role at an urgent care clinic prior to moving into academia. Her research interests include the areas of leadership and management, emotional intelligence, and medical errors.

\section{REFERENCES}

1. Adams, J., Jaffe, W., \& Rosenbloom, M. (2001). Patient care efficiency and medical error reduction using pda-based medical information. Academic Emergency Medicine, 8(5), 587-599.

2. Cooper, J. B. (2001). Current research on patient safety in the United States. Chicago: National Patient Safety Foundation. 
3. Corrigan, J. M., Donaldson, M. S., \& Kohn, L. T. (2000). To err is human: Building a safer health system. Washington DC: National Academy Press.

4. MacReady, N. (2000). Second stories, sharp ends: Dissecting medical errors. The Lancet, 355(9208), 994. Retrieved May 24, 2001, from http://pdf.thelancet.com/pdfdownload?uid=llan.355.9208.news.1895.1\&x=x.pdf

5. $\quad$ Noe, R. (2002). Employee training and development. McGraw-Hill.

6. O'Leary, D. S. (2000, February). Statement of the Joint Commission on Accreditation of Healthcare Organization. Statement presented at the United States Senate subcommittee on labor, health and human services, and education of the Senate committee on appropriations, Washington DC: Joint Commission of Accreditation of Healthcare Organizations.

7. O'Leary, D. S. (2000). Accreditation's role in reducing medical errors. Joint Commission on Accreditation of Healthcare Organizations. Oakbrook Terrace, IL: Joint Commission on Accreditation of Healthcare Organizations.

8. Pate, B., \& Stajer, R. (2001). The diagnosis and treatment of blame. Journal for Healthcare Quality, 23(1) 4-8.

9. $\quad$ Rothwell, W. J. (2002). The workplace learner. New York: AMACOM.

10. Rothwell, W. J. (1996). Beyond training and development. New York: AMACOM. 


\section{NOTES}

